University of Nebraska - Lincoln

DigitalCommons@University of Nebraska - Lincoln

$4-22-2020$

\title{
Post-dispersal factors influence recruitment patterns but do not override the importance of seed limitation in populations of a native thistle
}

\author{
Tatyana A. Rand \\ USDA-ARS Pest Management Research Unit, tatyana.rand@usda.gov \\ Natalie M. West \\ USDA-ARS Pest Management Research Unit, Natalie.West@ars.usda.gov \\ F. Leland Russell \\ Wichita State University, leland.russell@wichita.edu \\ Svata M. Louda \\ University of Nebraska - Lincoln, slouda1@unl.edu
}

Follow this and additional works at: https://digitalcommons.unl.edu/bioscifacpub

Part of the Biology Commons

Rand, Tatyana A.; West, Natalie M.; Russell, F. Leland; and Louda, Svata M., "Post-dispersal factors influence recruitment patterns but do not override the importance of seed limitation in populations of a native thistle" (2020). Faculty Publications in the Biological Sciences. 807.

https://digitalcommons.unl.edu/bioscifacpub/807

This Article is brought to you for free and open access by the Papers in the Biological Sciences at DigitalCommons@University of Nebraska - Lincoln. It has been accepted for inclusion in Faculty Publications in the Biological Sciences by an authorized administrator of DigitalCommons@University of Nebraska - Lincoln. 


\title{
Post-dispersal factors influence recruitment patterns but do not override the importance of seed limitation in populations of a native thistle
}

\author{
Tatyana A. Rand ${ }^{1} \cdot$ Natalie M. West ${ }^{1} \cdot$ F. Leland Russell ${ }^{2} \cdot$ Svata M. Louda $^{3}$
}

Received: 30 September 2019 / Accepted: 11 April 2020 / Published online: 22 April 2020

(c) This is a U.S. Government work and not under copyright protection in the US; foreign copyright protection may apply 2020

\begin{abstract}
Whether plant populations are limited by seed or microsite availability is a long-standing debate. However, since both can be important, increasing emphasis is placed on disentangling their relative importance and how they vary through space and time. Although uncommon, seed addition studies that include multiple levels of seed augmentation, and follow plants through to the adult stage, are critical to achieving this goal. Such data are also vital to understanding when biotic pressures, such as herbivory, influence plant abundance. In this study, we experimentally added seeds of a native thistle, Cirsium canescens, at four augmentation densities to plots at two long-term study sites and quantified densities of seedlings and reproductive adults over 9 years. Recruitment to both seedling and adult stages was strongly seed-limited at both sites; however, the relative strength of seed limitation decreased with plant age. Fitting alternative recruitment functions to our data indicated that post-dispersal mortality factors were important as well. Strong density-dependent mortality limited recruitment at one site, while density-independent limitation predominated at the other. Overall, our experimental seed addition demonstrates that the environment at these sites remains suitable for $C$. canescens survival to reproduction and that seed availability limits adult densities. The results thus provide support for the hypothesis that seed losses due to the invasive weevil, Rhinocyllus conicus, rather than shifting microsite conditions, are driving C. canescens population declines. Shifts in the importance of density-dependent recruitment limitation between sites highlights that alternate strategies may be necessary to recover plant populations at different locations.
\end{abstract}

Keywords Plant regeneration $\cdot$ Seed predation $\cdot$ Establishment limitation $\cdot$ Density-dependence $\cdot$ Platte thistle

\section{Introduction}

The extent to which plant populations are limited by seed availability (seed limitation) versus post-dispersal survival processes, such as the availability of suitable sites for establishment and growth (microsite limitation), is a

Communicated by Sarah M. Emery.

Tatyana A. Rand

tatyana.rand@usda.gov

1 Northern Plains Agricultural Research Laboratory, USDAARS Pest Management Research Unit, 1500 North Central Ave, Sidney, MT 59270, USA

2 Department of Biological Sciences, Wichita State University, 1845 Fairmount St., Wichita, KS 67260, USA

3 School of Biological Sciences, University of Nebraska, Lincoln, NE 68588, USA long-standing debate in plant ecology (Crawley 1990; Eriksson and Ehrlén 1992; Harper 1977). It is increasingly recognized that these processes can simultaneously or sequentially limit plant population abundance, leading to calls to move beyond a dichotomous view of their importance (Clark et al. 2007; Eriksson and Ehrlén 1992; Maron and Gardner 2000; Poulsen et al. 2007; Turnbull et al. 2000). Yet, studies disentangling the relative importance of seed limitation (e.g., that due to low seed production or low dispersal into a particular location), from post-dispersal density-dependent and independent survival limitations following seed input remain uncommon (Poulsen et al. 2007). Such studies are critical to evaluating the potential importance of biotic interactions, such as herbivory, in determining patterns of plant population abundance and distribution (Crawley 1989; Louda 1989).

The most direct way of evaluating seed limitation is by carrying out seed addition experiments. An increase in 
plant densities following seed addition has been considered evidence for seed limitation, while the absence of such an increase suggests strong post-dispersal limitation (Münzbergová and Herben 2005; Turnbull et al. 2000). Seed addition studies generally focus on recruitment to the seedling stage, a potentially critical bottleneck (Harper 1977). However, the relative importance of seed limitation in determining patterns of plant distribution or abundance is expected to decline as additional post-dispersal mortality factors impact later life stages (Clark et al. 2007; Ehrlén et al. 2006; Turnbull et al. 2000). A review of seed addition studies found that, in the small subset of studies examining the recruitment of both seedlings and eventual adults into previously unoccupied sites, occupancy declined from 64 to $23 \%$ from the seeding to adult stage (Turnbull et al. 2000). Similarly, in a seed addition study of six forest understory herbs, Ehrlén et al. (2006) found that the number of occupied patches declined over 3-11 years post-addition. Thus, following seed addition experiments through to the recruitment of reproductively mature adults is critical to rigorously assess the importance of seed limitation at the population level (Ehrlén et al. 2006; Poulsen et al. 2007; Turnbull et al. 2000; Zobel and Kalamees 2005).

Quantifying the relative importance of seed limitation and post-dispersal survival processes across the plant lifecycle has direct relevance to understanding the impact of herbivores on plant population dynamics (Crawley 1989; Louda 1989; Maron and Crone 2006). For plants with severe microsite limitation or strong density-dependent mortality, seed losses to herbivores will not necessarily translate into additional reductions in adult recruitment into the next generation. Thus, herbivores that limit seed production are predicted to impact plant densities only when seed losses are not compensated by reduced mortality (relatively weaker post-dispersal limitation) during later life stages. Furthermore, while density-independent factors such as microsite limitation can influence rates of population increase, only density-dependent processes can regulate population size (Halpern and Underwood 2006). Thus, quantifying the relative importance of density-dependent and density-independent sources of limitation is fundamental to understanding when and how pre-dispersal limits on seed input, such as floral and seed predation, influence plant population dynamics (Halpern and Underwood 2006; Kolb et al. 2007a; Maron and Crone 2006).

Examples in which pre-dispersal seed predators have strong impacts on plant recruitment in seed-limited systems, and those showing no impacts due to strong post-dispersal limitations have both been documented. Louda (Louda 1982, 1983) found that reducing floral herbivory on two species of Haplopappus increased seedling recruitment significantly where each plant species was sparse, altering the plants' predicted distribution. Similarly, Maron et al. (2002) found that adding seed, either directly or indirectly via the exclusion of floral herbivores, significantly increased the recruitment of seedlings and juveniles of two native Cirsium species. In contrast, Combs et al. (2011) found that strong microsite limitation due to competition with exotic grasses negated any benefits of seed addition to the recruitment of a rare native plant, Astragalus sinuatus, suggesting that excluding pre-dispersal seed feeders would only be effective when interspecific competitors are also removed. Finally, Garren and Strauss (2009) found that while seed addition initially increased seedling densities of the invasive weed, Centaurea solstitialis, strong density-dependent mortality, i.e., "self-thinning", resulted in no differences in adult densities between seed addition and control treatments. Their results suggest that significant seed losses to biocontrol agents may have limited impacts on population densities. Thus, determining herbivore impacts on plant abundance clearly requires a careful assessment of relative strengths of seed, density-independent and density-dependent limitations to adult recruitment.

One method for beginning to disentangle the relative importance of seed and post-dispersal limitations to plant recruitment involves evaluating the fit of alternative recruitment models to data from seed addition experiments that vary seed densities (Poulsen et al. 2007). Here, we used this approach to examine patterns of recruitment in a perennial monocarpic thistle, Cirsium canescens (Platte thistle). The goal was to gauge the potential importance of floral herbivore and pre-dispersal seed predators in the limitation of the abundance of this species in situ. Cirsium canescens declined precipitously in demography grids at a long-term study site in the upper Great Plains of North America 1991-2002 (Louda and Arnett 2000; Rose et al. 2005). Native inflorescence-feeding insects significantly reduce seed matured by $C$. canescens at this site, and these seed reductions result in reduced recruitment of both seedlings (Louda et al. 1990) and subsequent reproductive adults (Louda and Potvin 1995; Louda et al. 1990).

The arrival of Rhinocyllus conicus, an introduced invasive weevil, reduced seed production by this species even further (Louda et al. 1997, 2011; Rand and Louda 2012). This event is hypothesized to be the driver of observed declines in $C$. canescens numbers in long term demography grids (Louda 1998; Louda and Arnett 2000; Rose et al. 2005). However, population declines in demography grids could alternatively reflect changes in environmental conditions that limit establishment and survival, such as increases in competition as succession progresses (Harper 1977). In fact, previous work has shown that competition with native grasses can limit seedling establishment of $C$. canescens (Louda et al. 1990). However, the degree to which the recruitment of $C$. canescens is limited by seed availability vs. post-dispersal survival processes, in the era following $R$. conicus invasion 
and concomitant population declines, has not been experimentally evaluated. In this study, we monitored thistle populations over 19 years at two sites to assess whether initially reported declines in $C$. canescens densities were spatially and temporally consistent. We also carried out seed addition experiments to evaluate the relative importance of seed, density-dependent, and density-independent limitations to the recruitment of $C$. canescens seedlings and adults. The study was replicated at two long-term study sites in the Sand Hills prairie in Nebraska, USA, the center of $C$. canescens distribution. A finding of strong seed limitation, even when post-dispersal limitations are taken into account, would provide support for the hypothesis that seed losses associated with $R$. conicus invasion are a cause of population declines. Alternatively, if post-dispersal limitations dominate, then other environmental changes, such as increased competition with grasses or altered climatic conditions, are more likely driving the observed population declines. Our study had two objectives: (1) evaluate the evidence for seed limitation as the cause of $C$. canescens population declines; and, (2) evaluate the relative importance of seed, density-dependent and density-independent limitations in predicting patterns of recruitment to both the seedling and adult stages.

\section{Methods}

\section{Study system and establishment of demography grids}

Cirsium canescens (Platte thistle) is a relatively sparse native thistle species restricted to prairie grasslands on sand and gravelly soils in the upper Great Plains states of Nebraska and Wyoming and in montane valleys of the southern Rocky Mountains (Kaul et al. 2007; Keeler et al. 1980). Its monocarpic life history involves a 1-8 year juvenile rosette phase, before becoming a reproductively mature adult that flowers, sets seed and dies (Louda and Potvin 1995; Rose et al. 2005).

This work was done at two Nature Conservancy Preserves, separated by $330 \mathrm{~km}$ : Arapaho Prairie Preserve (APP) in Arthur County and Niobrara Valley Preserve (NVP) in Keya Paha County, in the Sand Hills of Nebraska, in upper Great Plains, USA. The Sand Hills vegetation is a distinctive mix of tallgrass and midgrass prairie species (Kaul et al. 2007). APP was managed by haying the lowland study areas in late summer on a 4-year rotation. NVP was managed for sustainability by low intensity, rotational cattle grazing.

Four demography grids $(12 \mathrm{~m} \times 12 \mathrm{~m})$ were established within prairie grass vegetation at APP and NVP in 1990 (Rose et al. 2005). All plants within each demography grid at each site were individually numbered with aluminum tags, and their fate followed from 1990 to 2009. Throughout the study, new plants in each of the demography grids were tagged with a unique number. Plants were surveyed each year late in the plant's growing season (12-20 July). On each sampling date, we recorded and mapped the number and identity of live, dead and missing plants and quantified growth stage (seedling, rosette or flowering adult) of all live plants.

To summarize the overall numerical pattern and determine whether initially documented declines in $C$. canescens at APP persisted in the decade following initial reports, and whether a similar pattern was observed at NVP, we summed the small number of flowering adults observed across all demography grids at each site for each year of the survey (1990-2009). These numbers were then converted to densities of adults per meter square to facilitate comparisons with the main results from the seed addition experiments.

\section{Seed addition experiments}

In July 2000, we randomly chose the northwest quadrant for the first two experimental blocks, and then placed two experimental blocks into the opposing southeast quadrant within each of the four demography grids at each site. Blocks within each experimental quadrant were placed in the west half of the quadrant. The exception was that one demography grid at NVP had only two blocks, instead of four, because of limited seed availability. The experimental blocks covered one quarter of the total demography grid area; natural recruitment continued within each demography grid.

Each experimental block was composed of 7 rows, with each row containing 4 plots $(25 \mathrm{~cm} \times 25 \mathrm{~cm})$; each plot was separated by $10 \mathrm{~cm}$ from the next plot. Rows 1,4 and 7 were control plots, with no seeds added. These plots provided an estimate of recruitment potential from the ambient seedbank. Rows 2, 3, 5 and 6 were experimental plots with seeds added to the plots: 5, 10, 20 and 40 seeds, respectively. This provided 12 control plots and 16 experimental plots, with 4 plots of each of the 4 seed augmentation levels, per block (total $N=448$ and 392 plots, using a total of 4800 seeds at APP and 4200 seeds at NVP). This design was chosen to increase the relative number of experimental plots while distributing control plots throughout each block.

Seeds were collected from $\sim 20$ bolting haphazardly selected individuals (census plants: Rose et al. 2005) at four locations near the grids at each experimental site. Seeds were collected in 1999 and supplemented with seeds collected within the year of seed addition (2000). Only fully inflated, undamaged seeds were used. Seeds were planted by pushing each seed into the soil $\sim 1 \mathrm{~cm}$, haphazardly spread throughout the plot, on the 18-22 July 2000; seed planting reduced wind movement effects. Post-dispersal seed predation on this species is insignificant to its recruitment dynamics within grass vegetation (Louda et al. 1990). Data 
collection consisted of counts and mapping of $C$. canescens plants per plot by stage-new seedlings (with at least one cotyledon), juvenile rosettes, flowering adults-in late May to mid-June each year (2001-2009).

To compare general, site-level, patterns of adult recruitment within the experimental seed addition plots to broader patterns observed in the demography grids, we totaled the number of adults observed across all experimental plots and levels of seed augmentation at each site in each year. Adult numbers in seed addition plots were then compared with those in both experimental control plots (for which cumulative adult densities were also calculated across plots for each site in each year), and those in demography grids. To facilitate comparisons with densities in the much larger demography grids, abundances in seed addition experiments were converted to the number of adults per meter square.

\section{Estimating seed, density-dependent and density-independent limitations}

To test for seed limitation, we evaluated whether seed addition increased recruitment relative to no-addition control plots. For each site, we compared mean recruitment at each augmentation level to the experimental controls using a generalized linear model with a binomial distribution followed by a post hoc Dunnett's test (R Core Team 2019; glht in multcomp package). For the seed addition plots, recruitment was quantified as the number of successful recruits given the number of seeds added. The experimental controls represented ambient recruitment potential from local sources and were expected to have recruits despite 0 seeds added. Therefore, control plot recruitment was entered into the binomial model as either [0 success 1 failure] in plots with no recruitment, or [the number recruitedl0 failures] if there were plants recruited. Mean recruitment significantly higher than the controls was considered evidence of seed limitation.

We adapted an analytical framework from Poulson et al. (2007) to evaluate the importance of seed limitation relative to post-dispersal density-dependent and density-independent survival limitations in predicting patterns of seedling and adult recruitment. Within the framework of Poulson et al. (2007), the relative strength of limitation is described by the increase in recruitment achieved when a constraint is completely removed. The relative importance of seed, densitydependent, and density-independent constraints can, therefore, be evaluated by comparing fitted models predicting recruitment with increasing seed augmentation that include these three processes separately and in combination. A constraint's "relative importance" in this case specifically refers to the value of including that constraint (via $S, P_{0}$, or $R_{\max }$, defined below) in models predicting recruitment compared to models where it is excluded. Importance is, therefore, quantified in a likelihood framework, and analogous to the use of this term in other model fitting contexts (e.g., Burnham and Anderson 2002). The full description and theory behind this approach can be found in Poulson et al. (2007); here, we summarize points relevant to our implementation.

We used a nested models approach to compare the fits of our seedling and adult recruitment data across four models of plant recruitment based on a two-parameter Beverton and Holt (1957) function,

$R=\frac{P_{0} S}{1+\left(P_{0} S / R_{\max }\right)}$

where $R$ is the number of recruits (that is, seedlings or adults) that emerge from an initial augmentation of $S$ seeds. $P_{0}$ is the proportion of plants recruited in the absence of density effects (density-independent recruitment), and $R_{\max }$ is the maximum number of potential recruits (where density-dependence saturates recruitment). In the absence of density-dependence, when $P_{0}$ equals 1 all the added seeds recruit and seed limitation dominates. However, seed limitation becomes less important as density-independent mortality increases $\left(P_{0}\right.$ nears 0$)$ and recruitment becomes low even at high levels of seed augmentation; recruitment is completely prohibited at $P_{0}=0$. Thus, seed limitation is effectively either greater than or equal to density-independence (Poulson et al. 2007). $R_{\max }$ reflects the augmentation level beyond which density-dependence prohibits any new recruits. The relative importance of density-dependence is low when seed densities are well below saturation. Therefore, a system with a high $R_{\max }$ relative to augmentation or ambient seed availability will be strongly seed limited. Because Beverton-Holt simplifies to a linear function as $R_{\max } \rightarrow \operatorname{Inf}$ (i.e., when there is no recruitment ceiling), fitting alternate parameterizations provides a means of incorporating both linear and nonlinear processes for comparison. We fit different recruitment models, using maximum likelihood, to the total number of seedlings and adults recruited per plot separately at each site across all years, and compared best-fit models of each recruitment function using likelihood ratio tests and AIC weights. Below, we outline the general approach adapted from Poulsen et al. (2007), followed by the specifics of model fitting and parameter estimation.

\section{General overview}

For seed limitation to be detected, seed addition should increase recruitment $(R)$ above the naturally occurring ambient recruitment $\left(R_{\mathrm{amb}}\right)$. Thus, for recruitment purposes, $S$ (number of seeds added) would actually be the sum of the number of seeds added experimentally $(A)$ and the number of recruits expected under ambient conditions $\left(S_{\text {amb }}\right.$, or $A=0)$. The simplest model fits recruitment with seed limitation only $\left(R_{\mathrm{s}}\right.$ : no density-independent or density-dependent 
limitation; parameters fixed at $P_{0}=1$ and $R_{\max } \rightarrow$ Inf), and estimates $S_{\mathrm{amb}}$ :

$R_{S}=A+S_{\mathrm{amb}}$

where $A$ is the number of seeds added $(A=5,10,20$, or 40 seeds). $S_{\text {amb }}$ provides an estimate of the ambient seed pool already present in the environment. Low values of $S_{\text {amb }}$ would associate with high seed limitation in the absence of post-dispersal limitation.

The second and third models both estimate two parameters: $S_{\text {amb }}$ and either $P_{0}$, for an estimate of density-independent recruitment, or $R_{\max }$, for an estimate of densitydependent recruitment. Thus, the second model [seed plus density-independent limitation $\left(R_{\mathrm{S}, \mathrm{DI}}:\right.$ no density-dependence: $R_{\max } \rightarrow$ Inf, estimating $P_{0}$ and $\left.S_{\text {amb }}\right)$ is:

$R_{S, D I}=P_{0}\left(A+S_{\text {amb }}\right)$

In this scenario, relatively high values of $P_{0}$ (weak density-independence) would associate with stronger seed limitation.

The third model [seed plus density-dependent limitation $\left(R_{\mathrm{S}, \mathrm{DD}}:\right.$ no density-independence: $P_{0}=1$, estimating $S_{\mathrm{amb}}$ and $\left.R_{\max }\right)$ ] is:

$R_{S, D D}=\frac{A+S_{\mathrm{amb}}}{\left.1+\left[\left(A+S_{\mathrm{amb}}\right) / R_{\max }\right)\right]}$

High $R_{\max }$ relative to seed input would associate with stronger seed limitation; however, density dependence would strengthen as seed augmentation approaches $R_{\max }$.

The fourth model included all three possible parameters: ambient seed rain plus both density-independent and density-dependent limitation (the full Beverton-Holt model: estimating $S_{\mathrm{amb}}, P_{0}$, and $R_{\max }$ ) is:

$R_{S, D I, D D}=\frac{P_{0}\left(A+S_{\mathrm{amb}}\right)}{\left.1+\left\{\left[P_{0}\left(A+S_{\mathrm{amb}}\right)\right] / R_{\max }\right)\right\}}$

We first fit the 1- and 2-parameter models, and compared each 2-parameter model to that of the simplest, 1-parameter model (Eq. 2 versus 3 or 4) using likelihood ratio tests. Significantly different models were then compared by AIC weights (Burnham and Anderson 2002; Bolker 2008). This step allowed us to evaluate the relative importance of seed versus density-dependent and densityindependent processes separately. The best fit 2-parameter model (either density-independent or density-dependent), based on an AIC weight difference of 2 or greater, was then compared to the full 3-parameter model (Eq. 5) with a likelihood ratio test and via AIC weights. If there was no difference between the best fit 2-parameter model and the 3-parameter model, the 2-parameter model was chosen as the most parsimonious solution.

\section{Model fitting and comparisons}

All analyses were performed in R v3.6.1 (R Core Team 2019). For each site, we totaled the number of seedlings and adults recorded per plot across all years. No new seedlings recruited into the experimental plots after 2005, and adults did not appear in plots until 2003. Thus, data for seedlings represent recruitment over the years 2001-2005, and adults over the years 2003-2009. We fit each recruitment function using maximum likelihood to generate parameter estimates and assuming a negative binomial data distribution. Parameter sweeps for $S_{\text {amb }}$ were bounded at 0 when necessary to stabilize model fitting. We then compared models using likelihood ratio tests and AIC tables, using the R package bbmle (Bolker and R Core Team 2017). We plotted the curves fitted using parameter estimates and overlaid the mean number of individuals recruited per plot at each level of seed augmentation, including control plots (no seeds added), in each life stage at each site. For illustration, we used bootstrapping to produce $95 \%$ confidence intervals around treatment means by sampling plot totals with replacement 2000 times and calculating the mean of each iteration. High and low values represent the 2.5 and 97.5 percentiles. Confidence intervals for adults were bias-corrected to account for asymmetry in the data.

\section{Results}

\section{Plant density in demography grids vs. seed addition plots}

The density of $C$. canescens adults continued to decline dramatically and remain low in long-term demography grids at APP, and also declined significantly at NVP, from 1990 to 2009 (Fig. 1a). Adult densities at both sites consistently exceeded 0.015 individuals per $\mathrm{m}^{2}$ in the first 7 years of the census (1990-1996), after which densities dropped; densities remained below this level over the next 13 years (Fig. 1a). Adult densities in the areas of these grids in which we experimentally augmented seed (Fig. 1b) were more than an order of magnitude higher than background densities at both sites over a 7-year interval, starting in the third year following seed addition (2003) when the first individuals reached adulthood, through the final, ninth year (2009) when the last individuals had reproduced and died (Fig. 1a,b). The one exception was 1 year at APP (2008) when no adults recruited. 
Fig. 1 a Density of adult $C$. canescens thistles in long-term demography plots at two study sites, Arapaho Prairie Preserve (APP) and Niobrara Valley Preserve (NVP), from 1990 to 2009. The invasive inflorescence feeding weevil was first observed at the sites in 1993. b Density of $C$. canescens adults recruiting to experimental seed addition plots within the longterm demography plots at these two sites

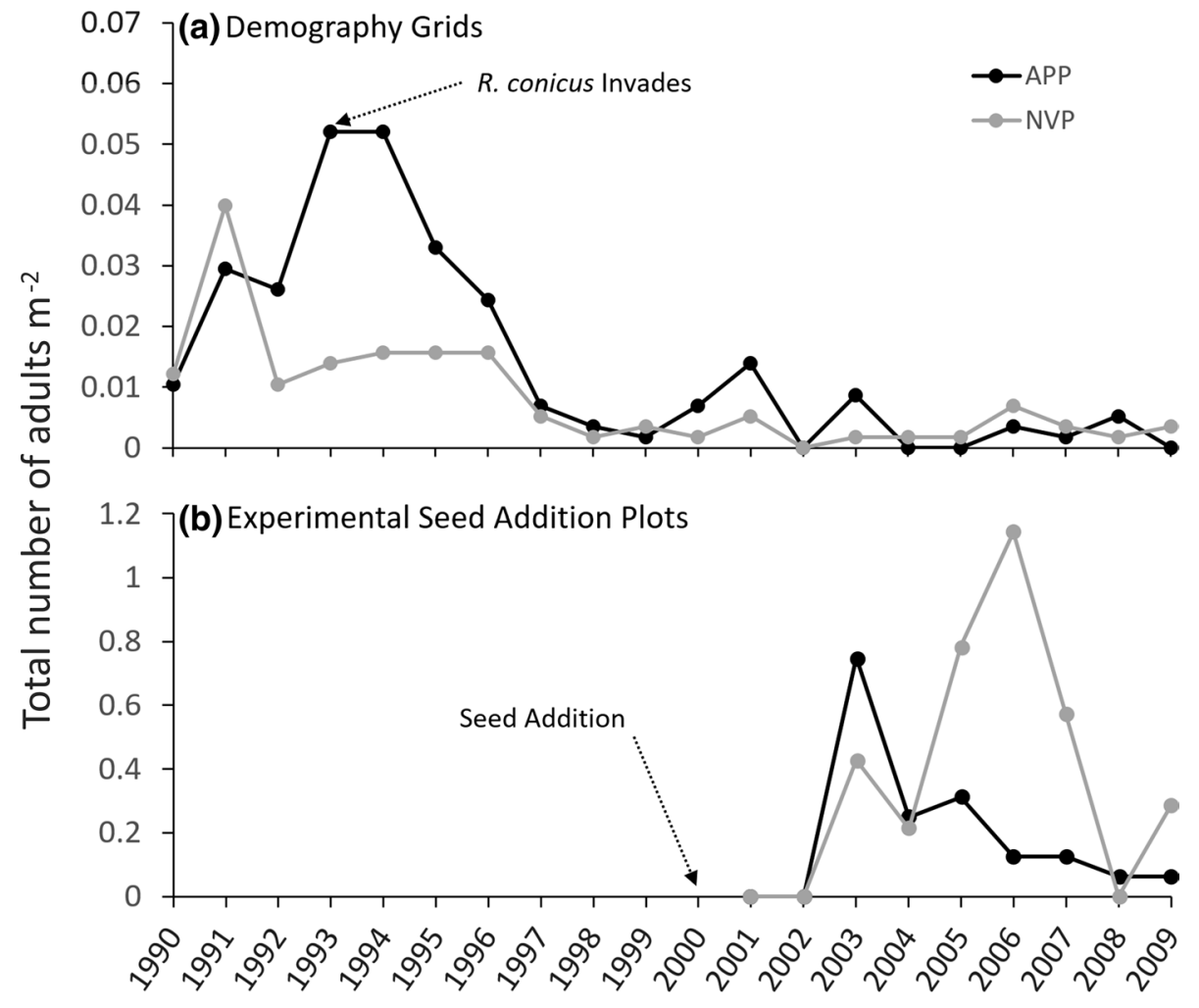

\section{Plant density in experimental seed addition vs. paired control plots}

Cumulative seedling recruitment in experimental control plots (with ambient levels of seed rain) was extremely low, with only 7 seedlings observed at APP $(N=3,2$, and 1 seedlings in 1, 1, and 2 plots, respectively) and 3 at $\operatorname{NVP}(N=1$ and 2 seedlings in 2 plots) over the entire 9 years of the experiment. Seedling densities were much higher in seed addition plots (across all levels of augmentation) relative to controls: 5.81 vs. 0.04 individuals/plot at APP and 5.50 vs. 0.02 individuals/plot at NVP. Overall, seedling recruitment rates in seed addition plots were relatively high: $31 \%$ at APP and $29 \%$ at NVP.

No adults recruited in control plots over the course of the experiment at either site. As observed for seedlings, seed augmentation increased recruitment of adults relative to control plots. Mean densities of adult plants per plot were 0.11 individuals/plot at APP and 0.21 individuals/plot at NVP. Overall, few seeds reached the adult stage: $0.6 \%$ at APP and $1 \%$ at NVP.

\section{Relative importance of seed, density-dependent and density-independent limitations}

Seed addition significantly increased seedling recruitment relative to controls at both sites and at all levels of seed augmentation $(p<0.001$ for the effect of seed addition and all post hoc comparisons with controls). An average of 2.08, $4.00,6.86$, and 10.28 seedlings recruited out of the 5-, 1020-, and 40-seed augmentation plots at APP (maximum of $5,9,14$, and 25 recruited, respectively; minimum recruitment $=0$ for all levels). For NVP, average seedling recruitment was $1.39,2.96,5.75$, and 11.88 at the four augmentation levels (maximums of 5,7,12, and 24, respectively; minimum $=0$ for all levels). Adult recruitment in each of the four levels was $0.11,0.08,0.13$, and 0.11 at APP and 0.04, $0.16,0.18$, and 0.48 at NVP [maximum: 3, 2, 2, 2 (APP) and $1,2,3,3$ (NVP), respectively; minimum $=0$ for all]. As no adults were recruited from the control plots, the seed addition versus control statistical comparison was not applicable. Adult recruitment was strongly seed limited.

Seed limitation alone, while important, was not sufficient to describe recruitment patterns (Fig. 2). The models including only ambient seed rain $\left(S_{\mathrm{amb}}\right)$ were never the best fit to the recruitment data at either site or life stage. Both densitydependence and density-independence were important for fitting the recruitment function, though their relative importance differed between sites and by life stage at one of the sites (Table 1).

At APP, the full model, including seed limitation plus both post-dispersal survival limitations (including $S_{\text {amb }}, P_{0}$, and $R_{\max }$ ), best fit the seedling recruitment data (Table 1, Fig. 2a). The model incorporating only seed limitation and density-dependence (estimating $S_{\mathrm{amb}}$ and $R_{\max }$ ) best fit the adult recruitment data (Table 1, Fig. 2c). However, at NVP, 

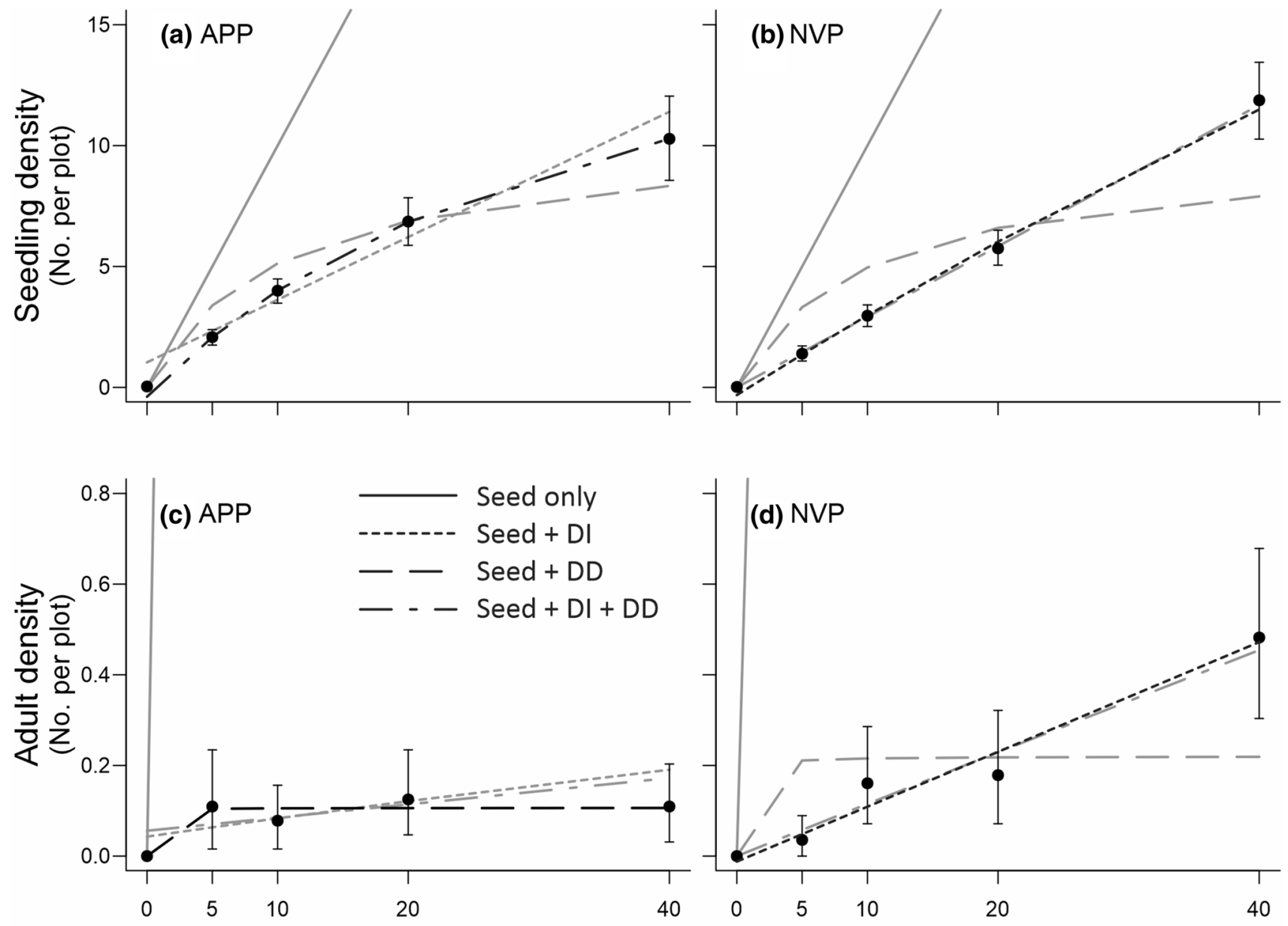

Seed density

(No. added per plot)

Fig. 2 Four recruitment function models, fitted to data from the seed addition experiment, for seedlings, $\mathbf{a}, \mathbf{b}$ and monocarpic adult plants, c, $\mathbf{d}$ at the two study sites: Arapaho Prairie Preserve (APP) and Niobrara Valley Preserve (NVP). Solid line represents the seed-limitationonly model. Dashed line represents the seed+density-independent model (S, DI). Dotted line represents the seed+density-dependent model (S, DD). Dash-dotted line represents the model including all three processes: seed-limitation, density-independent-limitation, and density-dependent-limitation (S, DD, DI). Best-fit models are highlighted as bold black lines; other models are displayed in gray
Table 1 Comparison of recruitment models fitted with combinations of seed and postdispersal limitation for seedling and adult stages of $C$. canescens

\begin{tabular}{|c|c|c|c|c|c|}
\hline \multirow[t]{2}{*}{ Life stage } & \multirow[t]{2}{*}{ Site } & Seed only (S) & $\begin{array}{l}\text { Seed }+ \text { density-inde- } \\
\text { pendence }(S, D I)\end{array}$ & $\begin{array}{l}\text { Seed + density- } \\
\text { dependence (S, DD) }\end{array}$ & Full model (S, DD, DI) \\
\hline & & NLL & NLL, $P$ & NLL, $P$ & NLL, $P$ \\
\hline \multirow[t]{2}{*}{ Seedling } & APP & -749.58 & $-650.63, P<0.001$ & $-651.02, P<0.001$ & $-648.33, P=0.02$ \\
\hline & NVP & -624.66 & $-519.80, P<0.001$ & $-536.29, P<0.001$ & $-520.10, P=0.54$ \\
\hline \multirow[t]{2}{*}{ Adult } & APP & -122.04 & $-94.26, P<0.001$ & $-87.97, P<0.001$ & $-92.62, P=0.07$ \\
\hline & NVP & -172.78 & $-115.66, P<0.001$ & $-126.38, P<0.001$ & $-115.65, P=0.90$ \\
\hline
\end{tabular}

$N L L$ negative log-likelihood. $P$ values are from pairwise comparisons using likelihood ratio tests. The twoparameter models, seed + density-dependence (S, DD) and seed + density-independence (S, DI), were each analyzed pairwise relative to the seed limitation only model (S). The best-fit of the two-parameter comparisons using AIC was then compared to the full model (S, DD, DI). Bolded entries are the best-fit model overall. If there was no significant difference between the two- and three-parameter model, then the twoparameter model was considered the most parsimonious solution 
both seedling (Fig. 2b) and adult recruitment data (Fig. 2d) were best fit by the model that included seed limitation and only density-independence (estimating $S_{\text {amb }}$ and $P_{0}$, Table 1).

\section{Discussion}

Previously documented declines in $C$. canescens density at APP (Louda and Arnett 2000; Rose et al. 2005) persisted in the decade following initial reports, and a similar pattern was observed at our second site, NVP, more than $300 \mathrm{~km}$ away (Fig. 1a). These results significantly expand the spatiotemporal inference of previous work, indicating a temporally persistent and spatially broad, rather than localized, cause of population declines. Adult densities at both sites consistently exceeded 0.015 individuals per $\mathrm{m}^{2}$ in the first 7 years of the demography surveys, 1990-1996; after that, adult densities dropped below this level and never again achieved it through the end of the study in 2009 (Fig. 1a). The invasive weevil, Rhinocyllus conicus, was first documented in 1993 and rapidly built up populations on $C$. canescens over the next few years. This timing is consistent with the hypothesis that the addition of $R$. conicus seed predation was a cause of populations declines (Rose et al. 2005).

Our seed addition test provides the first experimental support for this hypothesis. Starting in 2003, when the first seeded individuals reached the reproductive adult stage, adult densities in the experimental seed addition plots were more than an order of magnitude higher than the background levels observed in the demography survey grids, with the exception of 1 year at APP, when no adults recruited (Fig. 1a,b). These results demonstrate that recruitment of $C$. canescens at both sites continues to be strongly seed limited, even in the context of plant succession within our demography grids.

The pattern of strong seed limitation of seedling establishment and subsequent adult recruitment to the population, suggested by numbers in the demography grids, was substantiated by the experimental plot comparisons. Seedling densities in seed addition plots (summed across all levels of augmentation) were significantly higher (161 times higher at APP and 305 times higher at NVP) relative to those in control plots with ambient levels of seed availability. Furthermore, evidence of seed limitation persisted as plants developed into the adult stage. No adults recruited in control plots over the course of the experiment, while seed addition resulted in a total of 27 adults at APP and 48 adults at NVP recruiting in experimental plots. Thus, the experimental seed addition test provides clear evidence that the post-dispersal environment in demography grids at these long-term study sites remains suitable for $C$. canescens establishment and survival to reproduction, and that seed clearly limits seedling and adult densities. Experimental evidence for strong, persistent seed limitation in this study adds weight to previous work suggesting that reductions in seed production associated with the invasion by the novel pre-dispersal seed predator, $R$. conicus, limit plant abundance and threaten persistence (Rose et al. 2005). A finding of strong seed limitation, however, does not preclude the importance of post-dispersal factors in contributing to recruitment dynamics, since seed limitation and subsequent density-dependent and density-independent establishment and survival limitation are not mutually exclusive processes. The challenge is to quantify and disentangle their relative importance and how it varies through space and time (Poulsen et al. 2007). Furthermore, which post-dispersal pressures predominate can have very different implications for when and how predispersal limits on seed production, such as floral herbivory and seed predation, influence plant population dynamics (Halpern and Underwood 2006; Kolb et al. 2007a; Maron and Crone 2006).

Fitting recruitment functions relating the number of seedlings to experimental seed densities across the four levels of seed augmentation $(5,10,20$ or 40 seeds) further supported the importance of seed limitation in this system. Significant increases in the number of seedlings recruiting to plots with increasing levels of seed augmentation were observed at both sites (Fig. 2a, b), and seed addition significantly increased mean recruitment relative to control plots across all levels of augmentation. However, comparing the fit of the four alternative recruitment models indicated that seed limitation alone was never a best fit to the data.

Instead, model comparisons suggested that post-dispersal factors also strongly limited seedling recruitment (Table 1). Further, the comparisons indicated that the relative importance of density-dependent and density-independent processes varied between the study sites. At APP, the best-fit model included all three factors: seed limitation, densitydependent limitation and density-independent limitation. In contrast, at NVP no evidence for density-dependence was observed; the model including only seed and density-independent limitation best predicted seedling recruitment. By comparison, the review by Poulsen et al. (2007) found that in 14 of 36 cases (38.9\%) the best-fit seedling recruitment functions were non-linear (included a density-dependent term) while a majority of studies $(55.6 \%)$ showed a linear relationship that included seed and density-independent limitation. Thus, our findings re-enforce previous work demonstrating that density-dependent and independent processes both commonly limit seedling recruitment, and further demonstrate these post-dispersal limitations can vary in importance for the same species in different contexts.

Studies that examine the importance of seed limitation to adult recruitment are relatively rare; yet, such data are critical to gaining a complete picture of the importance of seed limitation in driving patterns of plant distribution and 
abundance (Ehrlén et al. 2006; Poulsen et al. 2007). In this study, seed limitation observed at the seedling stage persisted into the adult stage. All levels of seed addition at both sites increased recruitment relative to ambient controls, with $95 \%$ confidence intervals of only the 5 -seed treatment at one site, NVP, overlapping zero. The relative importance of subsequent limiting factors again differed between sites. At APP, the recruitment of reproductive adults was strongly negatively density-dependent such that no increase in adult densities was observed across our four levels of seed augmentation (Fig. 2c). Unlike for seedling recruitment, adding a density-independent term to the model for adults did not significantly improve model fit. The best-fit adult recruitment function included only seed limitation and densitydependent mortality. In contrast, at NVP, seed limitation of adult recruitment was evident across all levels of seed augmentation; the numbers of reproductive adults increased linearly as the number of seeds added increased (Fig. 2d).

Previous work suggests that the relative importance of seed limitation tends to decline with plant age (Clark et al. 2007; Ehrlén et al. 2006; Turnbull et al. 2000). Consistent with this view, we found that the strength of seed limitation relative to post-dispersal factors (density-dependent limitation at APP and density-independent limitation at NVP) declined for the later adult life stage, compared to the seedling stage, at both sites. The density-dependent carrying capacity for adults at APP $\left(R_{\max }\right.$, Table 2$)$ was considerably lower than for seedlings, eliminating overall gains in recruitment from adding seeds at high augmentation levels (i.e., 5 versus 10 or more seeds added). At NVP, density-independent limitation (represented by $P_{0}$, the expected proportion of seeds recruiting in the absence of density-dependence) was substantially stronger for adults: 0.11 , versus 0.29 for seedlings, a 68\% decrease. Overall, although post-dispersal limitations significantly modified initial patterns of seedling

Table 2 Estimates of ambient seed rain, density-independent recruitment, and carrying capacity from the best-fit models for each site and life-stage stage (bolded entries in Table 1)

\begin{tabular}{lllll}
\hline Life stage & Site & $P_{0}$ & $S_{\text {amb }}$ & $R_{\max }$ \\
\hline Seedling & APP & 0.47 & 0 & 23.05 \\
& NVP & 0.29 & 0 & {$[$ Inf] } \\
\multirow{3}{*}{ Adult } & APP & {$[1.0]$} & 0 & 0.11 \\
& NVP & 0.01 & 0 & [Inf] \\
\hline
\end{tabular}

Italics refer to parameters that are fixed (not estimated with likelihood) in the best-fit model

$P_{0}$ the proportion of plants recruited in the absence of density effects (density-independent paramater), $R_{\max }$ the maximum number of potential recruits, i.e., where density-dependence saturates recruitment (density-dependent parameter), $S_{a m b}$ the number of recruits expected under ambient conditions (seed limitation parameter) recruitment, seed limitation nonetheless persisted to affect the population reproductive potential at both sites.

While the factors limiting recruitment were relatively similar for the seedlings and adult stage within a site, they differed dramatically between the two sites. Strong density-dependence was only documented at APP, not NVP. Negative density-dependence, such as that observed at APP, is commonly observed in plant communities, and can be driven by strong intraspecific competition for resources or by density-dependent attack by other antagonists, such as herbivores or pathogens (Comita et al. 2014; Connell 1971; Janzen 1970; Watkinson 1980). Thus, site differences in the importance of density-dependence in our study could reflect variation in any factor that intensifies intraspecific competition (e.g., varying resource levels, such as moisture or nutrients) or differences in the prevalence or activity of herbivores or pathogens. We currently lack the data with which to assess the relative likelihood of these alternative scenarios. Foliar herbivores are important in the growth and mortality of other Cirsium spp. (Bevill et al. 1999), and pathogen attack has been recorded on $C$. canescens at APP (Louda, unpublished data). However, whether folivory or pathogen attack on $C$. canescens is density-dependent remains to be determined.

It is also possible that density-dependence could become important, even at NVP, if higher seed densities were used. Poulsen et al. (2007) found that density-dependence was most commonly observed in studies with maximum seed augmentation levels of $\geq 200,000$ seeds per $\mathrm{m}^{2}$, compared with a maximum of only 640 seeds per $\mathrm{m}^{2}$ ( 40 seeds added) used in this study. However, our seed augmentation levels were sufficient to bracket what would be expected to occur naturally at our sites. Previous studies documented an annual seed rain for $C$. canescens, prior to the invasion by $R$. conicus, of four seeds per $\mathrm{m}^{2}$ and virtually no seedbank (Potvin 1988). Furthermore, average levels of seed production for an individual plant, in the best case scenario (pre-dispersal seed predators reduced), has been estimated at 356-478 seeds (West and Louda 2018). This suggests that our high level of seed augmentation exceeded the numbers expected even if all viable seed end up directly under a parent plant. Thus, a major conclusion of our study remains that factors successively limiting recruitment in plant populations can vary considerably across sites.

Spatial variation in the factors limiting plant populations can importantly modulate where and how herbivores impact plant population dynamics (e.g., Kolb et al. 2007b; von Euler et al. 2014), with important implications for management. For example, differences in environmental conditions that alter the life-stage or processes limiting invasive plant populations may alter the efficacy of biological control agents (Myers and Sarfraz 2017; Shea et al. 2010). Similarly, recovery of rare plant populations by removing insect herbivores 
may only be effective under conditions where post-dispersal limiting factors, such as interspecific competition or pathogens, are absent or removed (Combs et al. 2011). In our study, adding five seeds at APP increased adult recruitment as much as adding 40 seeds due to strong density-dependent limitation on survival. This suggests a strong cap above which added seed does not increase adult recruitment. Thus reducing herbivores (e.g., via insecticide application) to augment seed production alone might be an inefficient approach to recover plant populations at this site unless post-dispersal density-dependent limitations are overcome. Determining the cause of density-dependent mortality would be important to developing potential strategies to limit its effects in areas of high seed availability. On the other hand, at NVP, a linear response in the density of adults recruited to increasing seed addition was observed. This suggests that herbivore reductions, and associated increases in seed production, at this site would have strong and predictable effects on $C$. canescens populations with no evidence for saturation. Our results thus suggest that strategies for the management of plant populations may vary substantially across sites, as the factors limiting populations shift.

The evolving debate over seed limitation versus post-dispersal survival limitation of plant populations increasingly supports a less absolutist view. Our results re-enforce that both can be important, and their relative strengths can vary through space and time. Quantifying the potential contributions of density-dependent and independent processes subsequent to significant seed limitation on plant recruitment in our system provides novel data critical to assessing the potential impacts of an invasive seed predator on the longterm persistence of this sparse native plant. Such data are also fundamental to expanding our understanding of how these factors interact with seed limitation to shape patterns of plant abundance more generally.

Acknowledgements We appreciate access to the study sites provided by The Nature Conservancy, Nebraska Chapter, and the support provided by both TNC staff and the University of Nebraska, Cedar Point Biological Station personnel. Research participation was made possible by grants from The Nature Conservancy (David H. Smith Post-Doctoral Fellowship to T. A. Rand), and from the National Science Foundation, Division of Environmental Biology (DEB96-15299, DEB-0414777) and the U.S.D.A., National Research Initiative (OEP2000-00848) for the other participants.

Author contribution statement SML conceived and designed the surveys and experiments. SML, TAR, FLR and NMW performed the surveys and experiments. NMW analyzed the data. TAR and NMW wrote the manuscript; SML and FLR revised the manuscript.

Funding This study funded in part by Grants from The Nature Conservancy (David H. Smith Post-Doctoral Fellowship to T. A. Rand), and from the National Science Foundation, Division of Environmental Biology (DEB96-15299, DEB-0414777) and the U.S.D.A., National Research Initiative (OEP2000-00848) for the other participants.

\section{Compliance with ethical standards}

Conflict of interest The authors declare that they have no conflict of interest.

\section{References}

Beverton RJ, Holt SJ (1957) On the dynamics of exploited fish populations. Chapman and Hall, London

Bevill R, Louda S, Stanforth L (1999) Protection from natural enemies in managing rare plant species. Conserv Biol 13:1323-1331. https ://doi.org/10.1046/j.1523-1739.1999.98450.x

Bolker BM (2008) Ecological models and data in R. Princeton University Press, Princenton, NJ

Bolker B, R Core Team (2017) bbmle: tools for general maximum likelihood estimation, 1st.0.20 edn. R Foundation for Statistical Computing, Vienna

Burnham KP, Anderson DR (2002) Model selection and multimodel inference a practical information-theoretic approach. Springer, New York

Clark C, Poulsen J, Levey D, Osenberg C (2007) Are plant populations seed limited? A critique and meta-analysis of seed addition experiments. Am Nat 170:128-142. https://doi.org/10.1086/518565

Combs JK, Reichard SH, Groom MJ, Wilderman DL, Camp PA (2011) Invasive competitor and native seed predators contribute to rarity of the narrow endemic Astragalus sinuatus Piper. Ecol Appl 21:2498-2509. https://doi.org/10.1890/10-2344.1

Comita LS et al (2014) Testing predictions of the Janzen-Connell hypothesis: a meta-analysis of experimental evidence for distance- and density-dependent seed and seedling survival. J Ecol 102:845-856. https://doi.org/10.1111/1365-2745.12232

Connell JH (1971) On the role of natural enemies in preventing competitive exclusion in some marine animals and in rain forest trees. In: den Boer PJ, Gradwell GR (eds) Dynamics of populations. Centre for Agricultural Publications, Wageningen, pp 2298-2312

Crawley MJ (1989) Insect herbivores and plant population dynamics. Ann Rev Entomol 34:531-564. https://doi.org/10.1146/annur ev.en.34.010189.002531

Crawley MJ (1990) The population dynamics of plants. Philos Trans R Soc Lond (B) 330:125-140. https://doi.org/10.1098/ rstb.1990.0187

Ehrlén J, Münzbergova Z, Diekmann M, Eriksson O (2006) Longterm assessment of seed limitation in plants: results from an 11-year experiment. J Ecol 94:1224-1232. https://doi.org/10.111 1/j.1365-2745.2006.01169.x

Eriksson O, Ehrlén J (1992) Seed and microsite limitation of recruitment in plant populations. Oecologia 91:360-364. https://doi. org/10.1007/BF00317624

Garren JM, Strauss SY (2009) Population-level compensation by an invasive thistle thwarts biological control from seed predators. Ecol Appl 19:709-721. https://doi.org/10.1890/07-0646.1

Halpern SL, Underwood N (2006) Approaches for testing herbivore effects on plant population dynamics. J Appl Ecol 43:922-929. https://doi.org/10.1111/j.1365-2664.2006.01220.x

Harper JL (1977) The population biology of plants. Academic Press, New York

Janzen DH (1970) Herbivores and the number of tree species in tropical forests. Amer Nat 104:501-528. https://doi.org/10.1086/282687

Kaul R, Sutherland D, Rolfsmeier S (2007) The flora of Nebraska. University of Nebraska-Lincoln, Lincoln

Keeler K, Harrison A, Vescio L (1980) The flora and Sandhills prairie community of Arapaho Prairie. Prairie Nat 12:65-78 
Kolb A, Ehrlén J, Eriksson O (2007a) Ecological and evolutionary consequences of spatial and temporal variation in pre-dispersal seed predation. Perspect Plant Ecol Evol Syst 9:79-100. https:// doi.org/10.1016/j.ppees.2007.09.001

Kolb A, Leimu R, Ehrlén J (2007b) Environmental context influences the outcome of a plant-seed predator interaction. Oikos 116:864 872. https://doi.org/10.1111/j.0030-1299.2007.15608.x

Louda SM (1982) Distribution ecology: Variation in plant recruitment in relation to insect seed predation. Ecol Monogr 52:25-41. https ://doi.org/10.2307/2937343

Louda SM (1983) Seed predation and seedling mortality in the recruitment of a shrub, Haplopappus venetus (Asteraceae), along a climatic gradient. Ecology 64:511-521

Louda SM (1989) Predation in the dynamics of seed regeneration. In: Leck MA, Parker VT, Simpson RL (eds) Ecology of soil seed banks. Academic Press, New York, pp 25-51. https://doi. org/10.2307/1939971

Louda SM (1998) Population growth of Rhinocyllus conicus (Coleoptera: Curculionidae) on two species of native thistles in prairie. Environ Entomol 27:834-841. https://doi.org/10.1093/ee/27.4.834

Louda SM, Arnett AE (2000) Predicting non-target ecological effects of biological control agents: evidence from Rhinocyllus conicus. In: Spencer NR (ed) Proceedings of the 10th international symposium on the biological control of weeds. Montana State University, Bozeman, MT, pp 551-567

Louda SM, Potvin MA (1995) Effect of inflorescence-feeding insects in the demography and lifetime fitness of a native plant. Ecology 76:229-245. https://doi.org/10.2307/1940645

Louda SM, Potvin MA, Collinge SK (1990) Predispersal seed predation, postdispersal seed predation and competition in the recruitment of seedlings of a native thistle in sandhills prairie. Am Midl Nat 124:105-113. https://doi.org/10.2307/2426083

Louda SM, Kendall D, Connor J, Simberloff D (1997) Ecological effects of an insect introduced for the biological control of weeds. Science 277:1088-1090. https://doi.org/10.1126/scien ce. 277.5329 .1088

Louda SM, Rand TA, Kula AAR, Arnett AE (2011) Priority resource access mediates competitive intensity between an invasive weevil and native floral herbivores. Biol Invasions 13:2233-2248. https ://doi.org/10.1007/s10530-011-0036-5

Maron JL, Crone E (2006) Herbivory: effects on plant abundance, distribution and population growth. Proc R Soc Lond (B) Biol Sci 273:2575-2584. https://doi.org/10.1098/rspb.2006.3587

Maron JL, Gardner SN (2000) Consumer pressure, seed versus safe-site limitation, and plant population dynamics. Oecologia 124:260 269. https://doi.org/10.1007/s004420000382
Maron JL, Combs JK, Louda SM (2002) Convergent demographic effects of insect attack on related thisltes in coastal vs. continental dunes. Ecology 83:3382-3392. https://doi.org/10.2307/3072087

Münzbergová Z, Herben T (2005) Seed, dispersal, microsite, habitat and recruitment limitation: identification of terms and concepts in studies of limitations. Oecologia 145:1-8. https://doi.org/10.1007/ s00442-005-0052-1

Myers JH, Sarfraz RM (2017) Impacts of insect herbivores on plant populations. Ann Rev Entomol 62:207-230. https://doi. org/10.1146/annurev-ento-010715-023826

Potvin MA (1988) Seed rain on a Nebraska Sandhills prairie. Prairie Nat 20:81-89

Poulsen J, Osenberg C, Clark C, Levey D, Bolker B (2007) Plants as reef fish: fitting the functional form of seedling recruitment. Am Nat 170:167-183. https://doi.org/10.1086/518945

R Core Team (2019) R: a language and environment for statistical computing. R Foundation for Statistical Computing, Vienna

Rand TA, Louda SM (2012) Exotic weevil invasion increases floral herbivore community density, function, and impact on a native plant. Oikos 121:85-94. https://doi.org/10.111 1/j.1600-0706.2011.19339.x

Rose KE, Louda SM, Rees M (2005) Demographic and evolutionary impacts of native and invasive insect herbivores on Cirsium canescens. Ecology 86:453-465. https://doi.org/10.1890/03-0697

Shea K, Jongejans E, Skarpaas O, Kelly D, Sheppard AW (2010) Optimal management strategies to control local population growth or population spread may not be the same. Ecol Appl 20:1148-1161. https://doi.org/10.1890/09-0316.1

Turnbull LA, Crawley MJ, Rees M (2000) Are plant populations seedlimited? A review of seed sowing experiments. Oikos 88:225-238. https://doi.org/10.1034/j.1600-0706.2000.880201.x

von Euler T, Ågren J, Ehrlén J (2014) Environmental context influences both the intensity of seed predation and plant demographic sensitivity to attack. Ecology 95:495-504. https://doi. org/10.1890/13-0528.1

Watkinson A (1980) Density-dependence in single-species populations of plants. J Theor Biol 83:345-357

West NM, Louda SM (2018) Cumulative herbivory outpaces compensation for early floral damage on a monocarpic perennial thistle. Oecologia 186:495-506. https://doi.org/10.1007/s0044 2-017-4027-9

Zobel M, Kalamees R (2005) Diversity and dispersal—can the link be approached experimentally? Folia Geobot 40:3-11 